\section{Damage and Recovery of Cranberry Vines from Exposure to Handheld Flame Cultivators}

\author{
Katherine M. Ghantous and Hilary A. Sandler ${ }^{1}$ \\ University of Massachusetts, Amherst, Stockbridge School of Agriculture, \\ UMass Cranberry Station, 1 State Bog Road, P.O. Box 569, East Wareham, \\ MA 02538
}

Wesley R. Autio
Stockbridge School of Agriculture, University of Massachusetts, Amherst,
MA 01003

Peter Jeranyama

University of Massachusetts, Amherst, Stockbridge School of Agriculture, UMass Cranberry Station, 1 State Bog Road, P.O. Box 569, East Wareham, MA 02538

Additional index words. cranberry (Vaccinium macrocarpon), flame weeding, mowing, torches, pruning, nonchemical weed control, thermal weeding

\begin{abstract}
Damage and recovery responses of four cranberry varieties ('Mullica Queen', 'Crimson Queen', 'Stevens', and 'Howes') to handheld propane flame cultivation (FC) torches were evaluated. All combinations of four levels of exposure duration of three FC torches (open flame $0,3,6$, and 9 seconds), infrared (IR) and IR with a $4.5-\mathrm{cm}$ metal spike $(0,15,30$, and 45 seconds), were tested on rooted cranberry uprights (vertical stems) planted in clay pots. Pots were subjected to a single treatment from one FC torch at one exposure duration; a glyphosate wipe was also included as a treated control (industry standard). Treatments were replicated five times. All cranberry plants were damaged by all levels of exposure duration as evident by visual damage ratings, reduced net cumulative stem lengths, reduced number of uprights, and reduced proportion of reproductive uprights when compared with untreated plants. All cranberry plants treated with glyphosate had total mortality; all cranberry plants from all varieties treated with FC survived, and all had net positive stem growth in the year after treatment except for 'Stevens' treated with open flame and IR with spike. The non-fatal response of cranberry to FC indicates that FC will cause less damage than glyphosate to cranberry plants that are incidentally exposed during spot treatment of weeds and thus could be integrated into weed control in certain situations, including organic farming.
\end{abstract}

Cranberry (Vaccinium macrocarpon Ait.) is a long-lived woody perennial with slender trailing stems that grows in acidic sandy soils. Cranberries in the United States are produced primarily in Massachusetts, Wisconsin, New Jersey, Washington, and Oregon and are important agricultural commodities for these states. Competition for resources between cranberry plants and weeds can depress cranberry yields, resulting in large annual crop losses (Patten and Wang, 1994; Swanton et al., 1993). Current weed management strategies

Received for publication 3 Apr. 2013. Accepted for publication 23 May 2013.

The research was made possible by funding from the Environmental Protection Agency Region 1 Pesticide Environmental Stewardship Program (PE-97152901-0).

We thank the Lotta Crabtree Graduate Fellowship in Agriculture Program for their support and Krystal DeMoranville and other Cranberry Station staff members for many hours of technical assistance. ${ }^{1}$ To whom reprint requests should be addressed; e-mail hsandler@umass.edu.
(Vaccinium myrtilloides and $V$. angustifolium) cultivation as a method of pruning to increase yield and aid in the control of weeds, pests, and pathogens (Eck and Childers, 1966). Historically, low-intensity burns were sometimes used on dormant cranberry vines as a way to remove old growth and stimulate new growth (Darrow et al., 1924). Although modern-day practices such as mowing have replaced this method, cranberry plants may be able to tolerate localized heat treatments primarily intended to control weeds.

Cranberry plants in a farm situation form a continuous mat of vegetation and thus present a logistical challenge for FC because weeds grow within the cranberry canopy structure. Although cranberry plants are not the target during FC treatments, treating weeds with FC may cause localized damage to cranberry plants immediately surrounding the weeds. Flame cultivation would ideally be used as a spot treatment for weeds growing in the cranberry canopy as well as on larger non-production areas where cranberry vines are not as abundant such as bed edges, ditches, and dikes.

The effect of FC on cranberry plants is not known and is an important determinant for developing recommendations for the use of FC on cranberry farms. A greenhouse study was conducted to measure cranberry response to $\mathrm{FC}$ in the absence of the naturally occurring variations found on cranberry farms. This study was performed in conjunction with a series of experiments testing three types of handheld propane torches (one open flame and two styles of IR) and varying exposure times on several species of perennial weeds (Ghantous et al., 2011, 2012). We hypothesized that 1) FC will cause damage to cranberry plants and that damage will increase with increasing exposure duration and vary by flame cultivator tool used; 2) cranberry plants will recover from FC treatment effect and recovery will vary with exposure duration and flame cultivator tool used; and 3) that there would be no difference in varietal response.

\section{Materials and Methods} pre- and postemergence herbicides (Sandler, 2011b).

Interest in reducing chemical inputs into cranberry systems has provided the motivation to evaluate methods such as FC as potential nonchemical options for weed control. Flame cultivation exposes plants to brief periods of high temperature causing the water in the plant tissue to expand rapidly, rupturing plant cells. Heat is thought to disrupt and destroy cellular membranes and lead to necrosis (Daniell et al., 1969; Ellwanger et al., 1973). Many different methods of FC are available ranging from open flames to IR (radiant heat), hot foam, and boiling water. Various FC methods have been used successfully in annual crops such as carrot, corn, onion, and potato as both a preemergence and postemergence weed control (Diver, 2002), but little work has been done on the use of FC in cranberry.

For decades, prescribed burning has been used in perennial woody lowbush blueberry
Vine source and propagation. Four cranberry varieties were tested. 'Mullica Queen' and 'Crimson Queen' were rooted in 2007 and tested in 2008, and 'Howes' and 'Stevens' were rooted in 2008 and tested in 2009. The study was conducted over a 2 -year period as a result of plant material availability. Greenhouse conditions, propagation methods, and plant handling were uniform during the study period. Cuttings for 'Mullica Queen' and 'Crimson Queen' were made from stolons (Integrity Propagation, Chatsworth, NJ). Cuttings for 'Stevens' and 'Howes' were taken from established cranberry farms located in Wareham, MA. Cranberry plants were cut and rooted according to previously published protocols (O'Connell et al., 2011). During establishment (May through September), plants were fertilized once per week with $15 \mathrm{~N}$ $7.0 \mathrm{P}-14.1 \mathrm{~K}\left(833 \mathrm{mg} \cdot \mathrm{L}^{-1}\right)$ by drenching the soil with the fertilizer solution. 
In December, cuttings were moved to cold storage $\left(5{ }^{\circ} \mathrm{C}\right)$ to accrue required chilling hours (Eady and Eaton, 1972). Rooted cuttings were returned to the greenhouse the next April. As the cutting developed roots, the aboveground portion supported additional stem and leaf growth and will henceforth be termed as a plant. Approximately 1 month before treatment, four cranberry plants were transplanted into a single clay pot (15 cm diameter, $15 \mathrm{~cm}$ long), which was the experimental unit. Pots were fertilized four times on a 3- to 4-week interval using the same fertilizer described previously. Although each cutting grows into a plant with multiple stems, four individual plants per pot were still identifiable.

Treatments application and data collection. Three handheld, propane-fueled cultivators were evaluated: open flame (OF, Weed Dragon vapor torch; Flame Engineering, LaCrosse, KS), IR and IR with a $4.5-\mathrm{cm}$ metal spike (IR, Infra-weed Eliminator and IRS, Dandy Destroyer, respectively; made by Puzzy Boy, Switzerland, distributed in the United States by Forevergreen, Blaine, WA) (Fig. 1).

The experiment was a randomized complete-block split-split plot design with four levels of variety as the main plot, three levels of FC tool type [OF, IR, and IR with spike (IRS)] as the subplot, and four levels of exposure duration as the sub-subplot; treatment combinations were replicated five times. Exposure duration levels were none, low, medium, and high durations $(0,3,6$, and $9 \mathrm{~s}$, respectively, for OF and $0,15,30$, and $45 \mathrm{~s}$, respectively, for IR and IRS). Timings were selected based on those used in a previous study (Ghantous et al., 2012) and are of equal intervals to allow comparisons between the torches. A glyphosate wipe was included as a treated control to represent the current practice for managing woody perennial weeds in cranberry (Sandler, 2011b).

Immediately before treatment, baseline counts of the number of cranberry stems in each pot were determined. In addition, the length of each stem was measured to the nearest millimeter. Water was applied to all plant foliage and soil with a handheld watering can for $10 \mathrm{~s}$ before and after $\mathrm{FC}$ treatments to minimize risk of fire. Pots intended for glyphosate treatments were also watered before treatment. Treatments were applied in mid-July when plants were actively growing.

Each pot was placed into the center of a $0.25-\mathrm{m}^{2}$ plot (simulating an area of cranberry bed that would be exposed during a FC spot treatment of weeds) before treatment. The OF and IR treatments were evenly applied to the entire $0.25-\mathrm{m}^{2}$ plot area for the duration of the exposure. Uniformity was achieved by using a digital stopwatch timer (Traceable Stopwatch 1045; Control Company, Friendswood, TX) and applying the treatment as a number of passes over the $0.25-\mathrm{m}^{2}$ area. The low, medium, and high treatments were one, two, and three passes, respectively. The OF was held $\approx 30 \mathrm{~cm}$ above the vines and the IR was physically in contact with the vines during application. The spike of the IRS was inserted into the center of the pot for the duration of the exposure.

Glyphosate treatments were applied using a small sponge. Cranberry plants were wiped until leaves appeared wet. In 2008, 'Mullica Queen' and 'Crimson Queen' plants were treated with a $12.5 \%$ a.i. (high end of the recommended range) glyphosate solution that resulted in $100 \%$ mortality. In 2009 , a midrange rate $(6.25 \%$ a.i. $)$ was selected for treatment of 'Stevens' and 'Howes' plants (Sandler, 2011b).

Visual evaluations of damage were made $1 \mathrm{~d}$ after treatment, 1 week after treatment (WAT), and 4 WAT. At 4 WAT, the amount of damage was not progressing and new growth was apparent, so evaluations after this point focused on cranberry plant recovery. Visual recovery evaluations were made to assess subsequent regrowth at 3 WAT, 7 WAT, and 18 WAT. The scale for damage evaluation for plants in each pot was: $0=$ all plants healthy; $1=$ plants show minor damage (less than $30 \%$ ); 2 = plants show moderate damage ( $30 \%$ to $60 \%) ; 3=$ plants show severe damage $(60 \%$ to $90 \%)$; and $4=$ plants show very severe damage or dead (greater than $90 \%$ ). The scale for recovery evaluations of each pot (four plants per pot) was: $0=$ all plants brown with no visible regrowth; $1=$ one or two

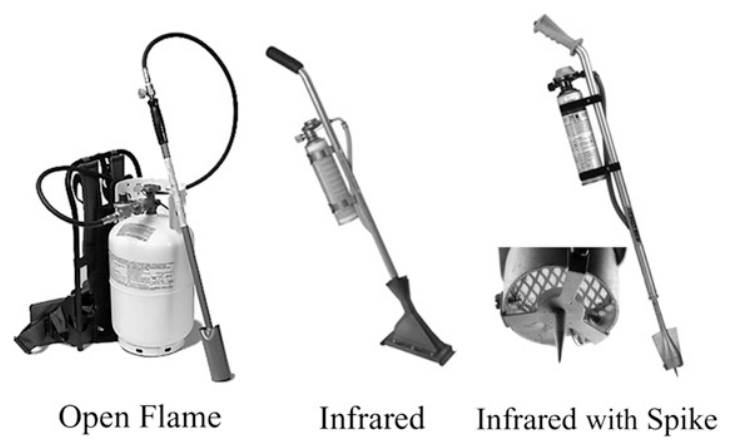

Fig. 1. Types of handheld propane torches evaluated. The OF is a torch with a $5.1-\mathrm{cm}$ bell that operates at a maximum capacity of $100,000 \mathrm{BTU}$ and approximate working flame temperature of $1121^{\circ} \mathrm{C}$. The IR has an enclosed propane flame that is projected onto a rectangular ceramic plate $8.3 \mathrm{~cm} \times 17.1 \mathrm{~cm}$ that provides radiant heat output up to $2500 \mathrm{BTU}$. The IRS has an enclosed flame that is projected onto a $4.5-\mathrm{cm}$ round ceramic plate with a $4.5-\mathrm{cm}$ metal spike protruding. Both the plate and the spike provide radiant heat output up to $6000 \mathrm{BTU}$. OF, open flame; IR, infrared; IRS, IR with spike.

plants have at least one to two new stem sprouts; 2 = three or four plants have at least one to two new stem sprouts; $3=$ all plants showing two or more new stem sprouts; $4=$ vigorous regrowth; and $5=$ no apparent damage/normal growth.

After treatment and the recovery period in the greenhouse in the year or treatment, cranberry plants entered dormancy and pots were removed from the greenhouse and put into cold storage $\left(5^{\circ} \mathrm{C}\right)$ in early December. Plants were returned to the greenhouse in early April after the chilling period was complete and allowed to resume growth. To assess reproductive potential, the final evaluation was done after the cranberry plants reached full bloom in mid-June, $\approx 11$ months after treatment (MAT).

Each pot was evaluated separately. All aboveground biomass was clipped from the pot. The stems were sorted and counted by type: runners (aboveground horizontal stolons) and vegetative or reproductive uprights (vertical stems). The length of each stem was measured to the nearest millimeter, and each sorted stem-type sample was then placed into paper bags. The bags were placed into an oven at $60^{\circ} \mathrm{C}$ for a minimum of $3 \mathrm{~d}$. The plant material was weighed to obtain dry biomass for each sample.

Correlation analysis indicated that stem length and biomass were highly correlated (data not shown; $P<0.001$ ). Although final biomass was determined, analyses were done using the change in cumulative stem length between final and baseline measurements per pot as a measure of cranberry recovery (net cumulative stem length) to account for preexisting difference between plants.

Data analysis. All data were analyzed using SAS (Version 9.2; SAS Institute Inc., Cary, NC). Normality was tested using Proc Univariate. Net cumulative stem length was calculated for each pot by subtracting the cumulative total length of all stems per pot before treatment from the cumulative total length of all stems per pot at the final evaluation. Proc Correlation was used to compute Pearson correlation coefficients for net cumulative stem length and final stem dry weight per pot. The proportion of flowering uprights was calculated by dividing the number of flowering uprights by the total number of uprights (per pot basis). Proportion data were arcsine-transformed before analysis of variance and converted to percentages for presentation. All cranberry plants treated with glyphosate died. Data from these treatments were not included in the statistical analysis.

Although two varieties were tested per year, this experiment was designed as a greenhouse study so that environmental and growing conditions were uniform. All plants were propagated and handled in a consistent manner, and year was not used as a variable, which is an accepted practice for greenhouse studies (Fernandez, 2007). Analyses of variance were performed using Proc Mixed with variety, FC tool type, exposure duration, and their interactions in the model statement for visual damage and recovery ratings, net 
cumulative stem length, number of upright stems, and proportion of upright stems that were reproductive. For data sets in which the main effect of exposure duration was significant, data were assessed for significant regression trends at the linear and quadratic levels using orthogonal contrasts in Proc GLM. For data sets in which the main effect of variety or FC tool type was significant, means were compared using Tukey's honestly significant difference (HSD) multiple comparisons test $(P \leq 0.05)$. Significant interactions between variety and FC tool type were sliced by variety and assessed with Tukey's HSD for FC tool type within variety. Significant interactions between FC tool type and exposure duration were sliced by FC tool type and regression trends were assessed for exposure duration within FC tool type. Exposure ranges are presented as categorical labels (none, low, medium, and high) to allow for combining of data into a single figure.

\section{Results and Discussion}

Visual damage ratings. All cranberry plants treated with glyphosate died. Presented ratings are from the last damage evaluation made 4 WAT. The effect of exposure duration on damage rating varied by $\mathrm{FC}$ tool type $(P \leq$ $0.001)$, but the interaction of variety and exposure duration was not significant. Overall, plants treated with the OF tool showed more damage than those treated with the IR or IRS tools. As exposure duration increased, the amount of damage increased for all FC tools (data not shown). As evident by the quadratic nature of the regression trends for all tools, the largest increase in the damage rating was seen between the control (no exposure) and low exposure, whereas the assessment of damage for the low, medium, and high exposures differed less from one another [IR y $=$ $-0.731 \mathrm{x}^{2}+3.286 \mathrm{x}+0.111\left(R^{2}=0.97\right)$. OF $\mathrm{y}=-0.993 \mathrm{x}^{2}+4.184 \mathrm{x}+0.196\left(R^{2}=0.94\right)$, IRS $\left.\mathrm{y}=-0.65 \mathrm{x}^{2}+3.035 \mathrm{x}+0.135\left(R^{2}=0.95\right)\right]$. Any small differences between the FC exposures (excluding the untreated) are likely not important from a practical weed management perspective. The advantage of using a longer exposure to improve weed control would likely outweigh any minor increase in crop damage incurred from the longer exposure.

The effect of variety on damage rating varied by $\mathrm{FC}$ tool type $(P=0.031)$. The interaction was the result of 'Howes' plants showing more damage than 'Crimson Queen' plants when treated with the IRS tool $(P=$ 0.021 , data not shown). Damage to the other varieties was similar across tool types.

Visual recovery ratings. Presented ratings are from evaluations conducted 18 WAT (before plants being moved into cold storage to accrue chilling hours) and are used to assess cranberry recovery within the same growing season as the FC treatments.

Like with damage ratings, the effect of exposure duration on recovery ratings varied by FC tool type for all varieties $(P \leq 0.001)$, but the interaction of variety and exposure duration was not significant (data not shown). Cranberry plants treated with IR had greater recovery compared with those treated with OF and IRS. The largest decrease in recovery rating was seen between the untreated (no exposure) and plants treated with low exposure, whereas differences in the amount of recovery rating among the low, medium, and high exposures were smaller in magnitude $\left[\right.$ IR y $=0.225 \mathrm{x} 2-0.965 \mathrm{x}+4.948\left(R^{2}=0.92\right)$. OF $\mathrm{y}=0.5123 \mathrm{x} 2-2.483 \mathrm{x}+4.855\left(R^{2}=0.97\right)$, IRS $\left.\mathrm{y}=0.563 \mathrm{x} 2-2.663 \mathrm{x}+4.888\left(R^{2}=0.96\right)\right]$.

The effect of variety on recovery rating varied by $\mathrm{FC}$ tool type $(P \leq 0.01)$. The interaction was the result of 'Howes' plants showing greater recovery than 'Crimson Queen' or 'Stevens' plants when treated with the IRS tool $(P=0.001$ and $P=0.047$, respectively, data not shown). No other varieties showed significant differences for the interaction.

Cranberry stem recovery. The effect of variety on the final net cumulative stem length of cranberry plants 11 MAT varied by FC tool type $(P=0.032)$ (Fig. 2). 'Crimson Queen', 'Mullica Queen', and 'Stevens' plants treated with the IR tool had significantly greater net cumulative stem length than plants treated with OF or IRS tools, which did not differ from each other. For 'Howes' plants, the IR and the IRS tools did not differ from one another and both had significantly greater net cumulative stem length than plants treated with the OF tool.

The effect of exposure duration on net cumulative stem length of cranberry plants varied by FC tool type $(P=0.008)$ (Fig. 3$)$ but not by variety. The effect of exposure duration was not significant for plants treated with the IR tool. Net cumulative stem length decreased quadratically as exposure duration increased for plants treated with the $\mathrm{OF}$ tool and decreased linearly for plants treated with the IRS tool. However, all net values were positive, indicating that even plants with the least amount of stems present had at least recovered to a level similar to that of their pre-treated state the previous year; the $\mathrm{OF}$ high exposure duration treatment mean was just above zero at $0.09 \mathrm{~cm}$. Even at the longest exposure, no cranberry plants died. All plants began to regrow within 3 WAT and all plants demonstrated normal seasonal response (i.e., evidence of endodormancy by foliar color change) and resumed typical growth after accruing sufficient chilling hours.

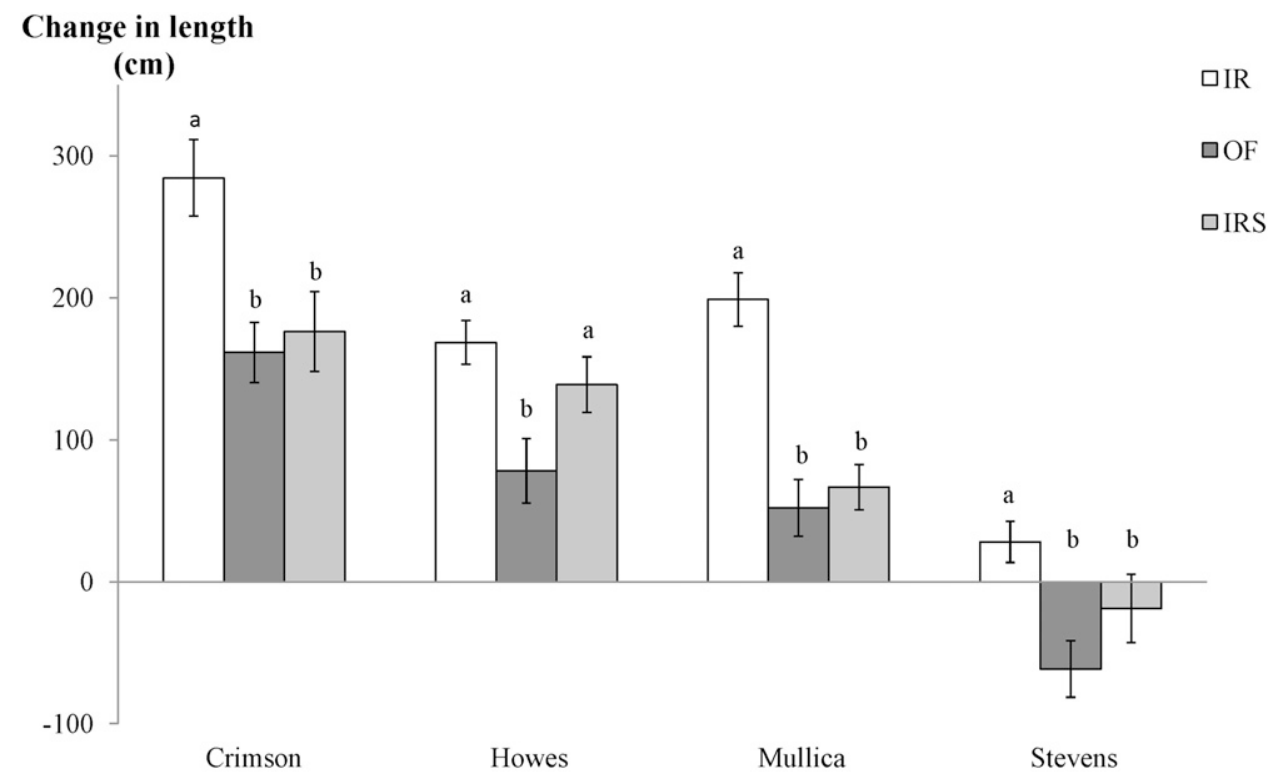

Fig. 2. Change in cumulative stem length per pot (mean $\pm S E, n=20)$ between pretreatment and final evaluation measurement $(\approx 11$ months after flame cultivation treatment) with infrared torch (IR), open flame torch (OF), or IR torch with spike (IRS). Means with similar letters within a variety are not significantly different according to Tukey's honestly significant difference $(P \leq 0.05)$. 
In contrast to FC treatments, all plants that were treated with the glyphosate wipe died (data not shown). Although cranberry plants are not intentionally exposed to glyphosate as part of routine cranberry growing practices, this herbicide is wiper-applied as a spot treatment for weeds and a portion of cranberry vines proximal to the weeds is typically injured during treatment. Although cranberry plants treated with FC were damaged, the non-fatal response indicates that cranberry plants that are incidentally exposed during spot treatment with $\mathrm{FC}$ will recover.

In addition to reducing net cumulative cranberry stem length, FC also reduced the number of total uprights per pot. Similar to the trends seen for the change in stem lengths, the effect of exposure duration on the number of total upright stems per pot varied by FC tool type $(P<0.001)$ (Fig. 4). The number of uprights decreased quadratically as exposure duration increased for plants treated with the OF and the IRS tool. Use of the IR tool at any exposure duration did not affect the number of uprights per pot. The main effect of variety was also significant $(P<0.001)$. 'Crimson Queen' and 'Howes' did not differ from one another, and both had significantly more uprights than 'Mullica Queen' or 'Stevens', which did not differ from one another (data not shown).

The reason for the differences in the cumulative net stem length or number of uprights as a response to FC tool type is unclear but may be the result of the design of the tools. The OF tool generates the highest working temperature, and the IRS tool has a spike that is inserted into the soil, which is intended to impact on root structures. The IR tool has a lower working temperature than the $\mathrm{OF}$ tool and lacks a soil spike.

Reproductive potential. The percentage of reproductive uprights the year after treatment decreased quadratically as exposure duration increased $(P \leq 0.001)$ (Fig. 5). The percentage of upright stems that are reproductive is an important contributor to yield in cranberry (Eaton and Kyte, 1978). The main effect of FC was also significant $(P=0.036)$. Plants treated with the OF tool had a lower percentage of uprights that were reproductive $(\overline{\mathrm{x}}=$ $4.3 \%)$ than plants treated with the IR tool ( $\overline{\mathrm{x}}=$ $7.7 \%$ ). IR did not differ from IRS, and IRS $(\overline{\mathrm{x}}=6.4 \%)$ did not differ from OF. In addition, variety significantly affected the percentage of reproductive uprights stems $(P \leq 0.01)$. 'Crimson Queen', 'Mullica Queen', and 'Stevens' did not differ from one another, but all had a higher percentage of reproductive uprights than 'Howes' (data not shown). 'Howes' is a native variety, whereas the other three are hybrids. Differences in reproductive potential are likely the result of innate differences between the varieties rather than any treatment effects (Caruso, 2008).

In this study, FC treatments caused damage to the cranberry stems present in the pot at the time of treatment. Most of the treated plants became defoliated and exhibited damage and/or death of exposed stems. The plants began to regrow 3 WAT, and this regrowth

Change in length

$\square$ IR

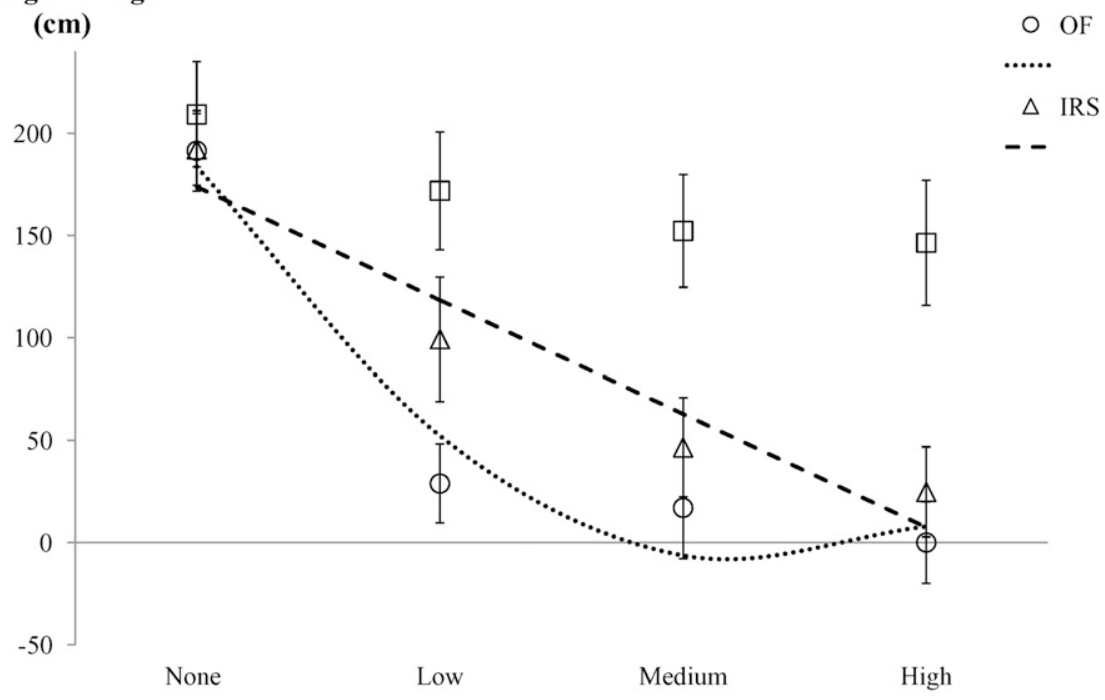

Exposure

Fig. 3. Change in cumulative cranberry stem length per pot (mean $\pm S E, n=20)$ between pretreatment and final evaluation measurement $(\approx 11$ months after flame cultivation treatment). Exposure of none, low, medium, and high correspond to $0,15,30$, and $45 \mathrm{~s}$, respectively for the infrared torch (IR) and the IR torch with spike (IRS) and to $0,3,6$, and $9 \mathrm{~s}$ for the open flame torch (OF). IR $=$ nonsignificant (NS). OF $\mathrm{y}=36.39 \mathrm{x}^{2}-167.77 \mathrm{x}+183.69\left(R^{2}=0.95\right)$. IRS $\mathrm{y}=-55.45 \mathrm{x}+173.89\left(r^{2}=0.92\right)$

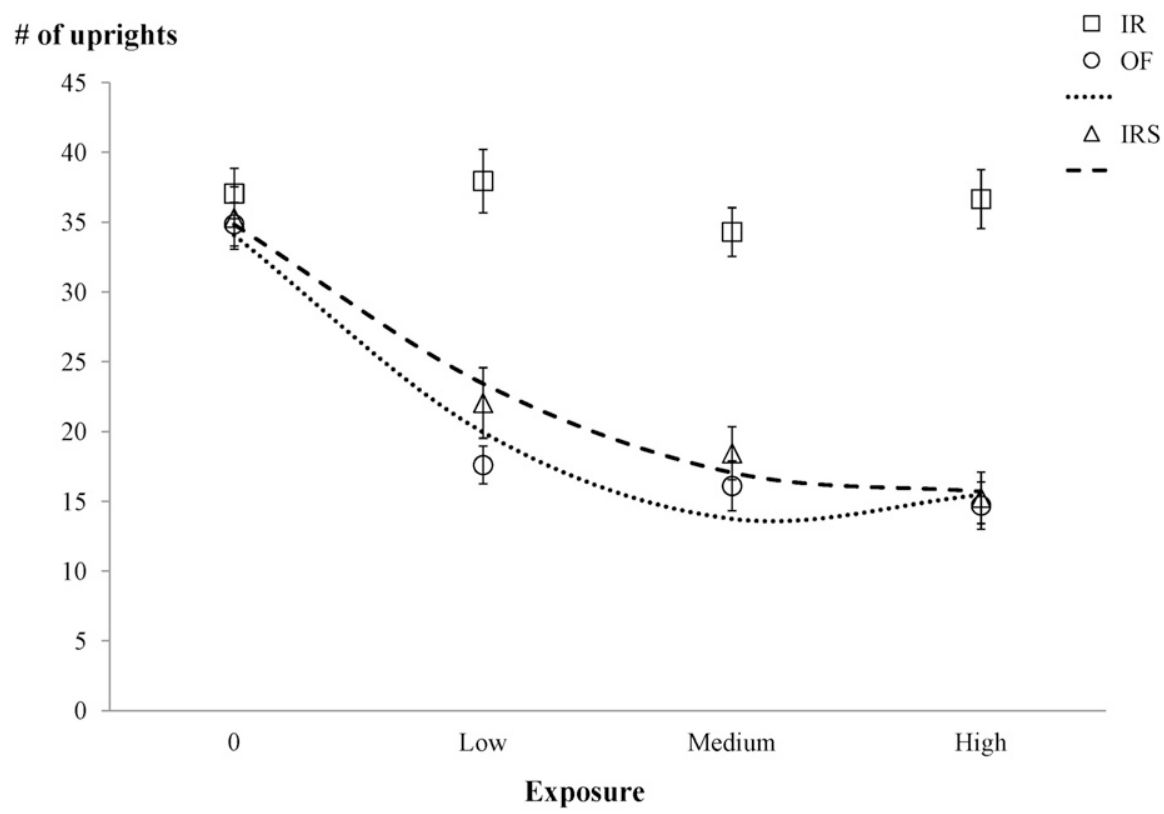

Fig. 4. Number of cranberry uprights per pot (mean $\pm \mathrm{SE}, \mathrm{n}=20)$ at final evaluation measurement $(\approx 11$ months after flame cultivation treatment). Exposure of none, low, medium, and high corresponds to 0 , 15,30 , and $45 \mathrm{~s}$ for the infrared torch (IR) and the IR torch with spike (IRS) and to $0,3,6$, and $9 \mathrm{~s}$ for the open flame torch (OF). IR $=$ nonsignificant (NS). OF $\mathrm{y}=3.96 \mathrm{x}^{2}-18.08 \mathrm{x}+34.07\left(R^{2}=0.95\right)$. IRS $\mathrm{y}=$ $2.51 \mathrm{x}^{2}-13.91 \mathrm{x}+34.84\left(R^{2}=0.98\right)$.

was typically in the form of new shoots emerging from the soil or the lowest parts of the plants and not seen as recovery of the existing older material (e.g., growing new leaves on stems existing before FC, recovery of the existing terminal bud). New uprights produced as a result of terminal bud loss were generated from lateral buds that are primarily vegetative in the first year of growth (Sandler, 2011a).
Previous pruning and mowing studies of cranberry beds showed that pruned or mowed vines had a reduction in fruit yield the year after treatment, and the reduction increased as the severity of pruning increased (Sandler, 2011a; Sandler and DeMoranville, 2009; Strik and Poole, 1991). The second year after pruning, vines typically produce greater yields than before pruning (Chambers, 1918). Flame cultivation treatments reduce vine stem length 
$\%$ reproductive

uprights

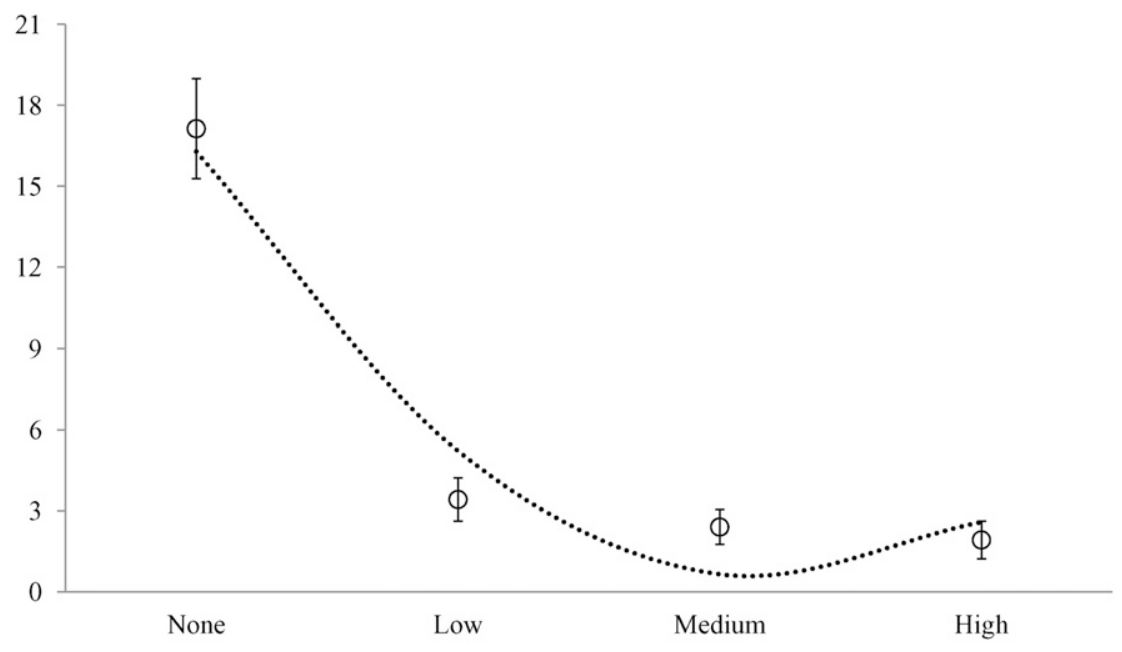

Exposure

Fig. 5. Percentage of reproductive cranberry uprights per pot (mean $\pm \mathrm{sE}, \mathrm{n}=60$ ) at final evaluation measurement $(\approx 11$ months after FC treatment). Exposure of none, low, medium, and high corresponds to $0,15,30$, and $45 \mathrm{~s}$ for the infrared torch (IR) and the IR torch with spike (IRS) and to $0,3,6$, and $9 \mathrm{~s}$ for the open flame torch $(\mathrm{OF}) \mathrm{y}=3.25 \mathrm{x}^{2}-14.32 \mathrm{x}+16.29\left(R^{2}=0.96\right) . \mathrm{FC}=$ flame cultivation

and are likely affecting vines in a similar manner to a heavy pruning or mowing.

Current data indicate that plants treated with FC will have reduced reproductive potential the year after treatment. Cranberry vines would be expected to recover to typical reproductive output in subsequent years provided no other limitations are imposed (Sandler and DeMoranville, 2009; Vanden Heuvel and Davenport, 2005). We speculate that if the plants had been followed for an additional year (second year after treatment), the percentage of reproductive uprights would have returned to levels comparable to the untreated controls.

Cranberry vine damage by exposure to $\mathrm{FC}$ was verified by reduced net stem length, lower number of uprights, and lower percentages of reproductive uprights when compared with untreated plants in the year after treatment. Flame cultivation did not kill treated cranberry plants, which began making new growth within 3 weeks of being treated. Damage and subsequent recovery were comparable to the response of cranberry vines after mowing or heavy pruning (Sandler, 2011a; Sandler and DeMoranville, 2009). Subsequent research should follow FC-treated vines into a second year after treatment to verify longterm response. In addition, future work should evaluate the response of cranberry vines in a farm setting where cranberry plants grow densely and create a continuous mat of vegetation to evaluate if a thick canopy could diffuse FC heat and mitigate a portion of the damage noted in this greenhouse study.

Flame cultivation has been demonstrated to be effective at controlling some weed species found in cranberry such as dewberry (Rubus spp.) and rushes (Juncus effusus) All torches were equally effective at controlling dewberry, whereas the IRS was less effective than the IR and OF at controlling rushes (Ghantous et al., 2011, 2012). Although there were minor response differences between the cranberry varieties tested, all showed recovery from FC damage irrespective of which FC tool was used or duration of exposure. Although the IR and IRS torches caused slightly less cranberry damage than the OF torch, the long exposure times of the IR and IRS (45 s compared with $9 \mathrm{~s}$, respectively) and possible lower efficacy of weed control form the IRS make them a less attractive option for weed control. An economic analysis showed that the time and cost of using an OF torch for spot control of weeds was similar to that of the common weed control practice of using a wick applicator to apply glyphosate to weeds (Sandler and Ghantous, 2011). In addition to being as cost-effective as glyphosate wipes, the non-fatal cranberry response to FC indicates that it will cause less damage to cranberry plants that are incidentally exposed during spot treatment of weeds than glyphosate.

Flame cultivation could be integrated into a sustainable and economical approach for weed control in certain situations. This technology would be applicable for conventional production as well as organic production and would ideally be used as a spot treatment for weeds growing in the cranberry canopy as well as on larger non-production areas where bed edges, ditches, and dikes.

\section{Literature Cited}

Caruso, F.L. 2008. Cranberry cultivars, p. 72-84. In: Sandler, H.A. and C.J. DeMoranville (eds.). Cranberry production: A guide for Massachusetts. cranberry vines are not as abundant such as
UMass Cranberry Station, CP-08, East Wareham, MA.

Chambers, F.S. 1918. Pruning experiments. Proc. 48th Annu. Mtg. Amer. Cran. Growers Assn.

Daniell, J.W., W.E. Chappell, and H.B. Couch. 1969. Effect of sublethal and lethal temperatures on plant cells. Plant Physiol. 44:1684 1689.

Darrow, G.M., H.J. Franklin, and O.G. Malde. 1924. Managing cranberry fields. Farmers' Bulletin 1401. USDA, Washington, DC p. 21.

Diver, S. 2002. Flame weeding for vegetable crops National Center for Appropriate Technology. 26 Mar. 2012. <https://attra.ncat.org/attra-pub/ summaries/summary.php?pub $=110>$.

Eady, F.C. and G.W. Eaton. 1972. Effects of chilling during dormancy on development of the terminal bud of the cranberry. Can. J. Plant Sci. 52:273-279.

Eaton, G.W. and T.R. Kyte. 1978. Yield component analysis in the cranberry. J. Amer. Soc. Hort. Sci. 103:578-583.

Eck, P. and N.F. Childers. 1966. Blueberry culture. Rutgers Univ. Press, New Brunswick, NJ.

Ellwanger, T.C.J., S.W. Bingham, and W.E. Chapell. 1973. Physiological effects of ultrahigh temperatures in corn. Weed Sci. 21:296299.

Fernandez, G.C.J. 2007. Design and analysis of commonly used comparative horticultural experiments. HortScience 42:1052-1069.

Ghantous, K.M., H.A. Sandler, W.R. Autio, and P. Jeranyama. 2011. Timing, duration and type of flame cultivator affects weed response in cranberry. Proc of the Northeastern Weed Science Society 65. p. 68

Ghantous, K.M., H.A. Sandler, W.R. Autio, and P. Jeranyama. 2012. Handheld flame cultivators as a management option for woody weeds. Weed Technol. 26:371-375.

O'Connell, J., H.A. Sandler, L.S. Adler, and F.L. Caruso. 2011. Controlled studies further the development of practical guidelines to manage dodder (Cuscuta gronovii) in cranberry production with short-term flooding. Renew. Agr. Food Syst. 26:269-275.

Patten, K.D. and J. Wang. 1994. Cranberry yield and fruit quality reduction caused by weed competition. HortScience 29:1127-1130.

Sandler, H.A. 2011a. Nitrogen and vine-harvest method affect cranberry vine production and yield. HortTechnology 21:87-97.

Sandler, H.A. 2011b. Weed management, p. 21-42. In: Sylvia, M.M. and N. Guerin (eds.). Cranberry chart book-Management guide for Massachusetts. UMass Amherst Cranberry Sta., East Wareham, MA

Sandler, H.A. and C.J. DeMoranville. 2009. Economic analysis of nitrogen rate on vine production and fruit yield of pruned cranberry beds. HortTechnology 19:572-579.

Sandler, H.A. and K.M. Ghantous. 2011. Economics of using hand-held flame cultivators for weed management in cranberry. 9 Mar. 2011. <http:// wssaabstracts.com/public/4/abstract-142.html>.

Strik, B.C. and A.P. Poole. 1991. Timing and severity of pruning effects on cranberry yield components and fruit anthocyanin. HortScience 26:1462-1464.

Swanton, C.J., K.N. Harker, and R.L. Anderson. 1993. Crop losses due to weeds in Canada. Weed Technol. 7:537-542.

Vanden Heuvel, J.E. and J.R. Davenport. 2005. Effects of light, temperature, defoliation, and fruiting on carbon assimilation and partitioning in potted cranberry. HortScience 40:16991704 . 